\title{
Airway management in pre-hospital critical care: a review of the evidence for a 'top five' research priority
}

\author{
K. Crewdson ${ }^{1 *}$ (D) M. Rehn ${ }^{2,3,4}$ and D. Lockey ${ }^{1,2,5}$
}

\begin{abstract}
The conduct and benefit of pre-hospital advanced airway management and pre-hospital emergency anaesthesia have been widely debated for many years. In 2011, prehospital advanced airway management was identified as a 'top five' in physician-provided pre-hospital critical care. This article summarises the evidence for and against this intervention since 2011 and attempts to address some of the more controversial areas of this topic.
\end{abstract}

Keywords: Airway management, Emergency medical services, Intubation

\section{Background}

Pre-hospital emergency anaesthesia (PHEA) and advanced airway management remains a controversial subject. There are mixed views about whether advanced interventions are beneficial or detrimental [1-4]. What is clear however, is that there is a small but identifiable group of patients with recognised indications for intubation, in whom basic airway manoeuvers are not sufficient to maintain adequate oxygenation, and advanced airway interventions are warranted at an early stage [5].

The quality of pre-hospital emergency airway management has progressed significantly. For many years intubation was usually only performed for patients in cardiac arrest or in those with an absent gag reflex, and was associated with a poor outcome $[6,7]$. The number of advanced airway interventions performed in the pre-hospital setting has increased significantly over recent years. A meta-analysis published in 2010 reported a total of 54,933 intubation attempts [8]. In a subsequent meta-analysis from 2006 to 2016, 125,177 intubation attempts were reported [9]. It is likely that one of the major factors contributing to these findings is the increasing number of physicians involved in pre-hospital care, particularly in European practice. This observation is borne out by further data from meta-analyses which

\footnotetext{
* Correspondence: kate.crewdson@nbt.nhs.uk

'Department of Anaesthesia, North Bristol NHS Trust, Southmead Hospital,

Southmead Way, Bristol BS10 5NB, UK

Full list of author information is available at the end of the article
}

reported only 127 intubation attempts by physicians up to and including 2009 [8], compared with 23,738 intubation attempts by physicians between 2006 and 2016 [9]. The recent interest in pre-hospital advanced airway management has generated more research in this area but the majority of studies are single centre retrospective database reviews, with significant heterogeneity in the design, methodology and endpoints, making interpretation and the generation of meaningful conclusions difficult $[10,11]$. Randomised controlled trials are difficult to conduct in a pre-hospital or major trauma setting due to issues around consent and inclusion criteria $[12,13]$.

In 2011, an expert consensus process identified advanced airway management as one of the top five research priorities in pre-hospital critical care [10]. Some of the most important questions remain the most difficult to answer, for example, what are the indications for pre-hospital advanced airway management, does it confer a survival benefit, which patients should receive it, who should deliver it? [10]. The aim of this article is to present the arguments for and against the practice of advanced pre-hospital airway management and PHEA and attempt to address some of the controversy surrounding this topic.

Is pre-hospital advanced airway management necessary? One method of addressing whether advanced airway interventions performed in the pre-hospital setting are actually necessary is to assess whether there is an unmet 
need for pre-hospital intubation. This can be determined by identifying the number of patients who arrive in the emergency department (ED) with indications for urgent tracheal intubation. Relatively few studies directly address this issue and those that do suggest that there is an unmet demand for urgent tracheal intubation for a proportion of trauma patients in whom basic airway manoeuvres are inadequate. One study from a pre-hospital physician-led service based in the United Kingdom (UK) investigated trauma patients who required any airway interventions. Despite the presence of ambulance personnel, $57 \%$ of patients still had airway compromise on arrival of the physician-led trauma team. All patients required emergency intubation on scene [5]. Unpublished data obtained by the author (KC) from the UK trauma audit and research network also suggests an unmet demand in the delivery of pre-hospital advanced airway management. In the United States, approximately $10 \%$ of trauma admissions require advanced airway intervention within the first 5 hours of hospital arrival; over half of the patients had indications for urgent intubation including reduced level of consciousness, hypoventilation or hypoxaemia, or airway obstruction $[14,15]$.

\section{Which patients need it?}

Emergency airway management in any setting has a significant risk of complications; [16] complication rates of up to $13 \%$ have been reported [17], and careful selection of the correct patients is part of improving the overall success of the procedure. There are some indications which require immediate airway intervention, including complete airway obstruction, failure to oxygenate or ventilate adequately, cardiac arrest or a Glasgow Coma Scale (GCS) less than 9 [18]. In some circumstances, basic airway techniques may provide temporary management of oxygenation and ventilation but advanced airway techniques are usually required to provide definitive airway control. There is considerable variation in the indications for pre-hospital emergency airway management. Datasets produced from analysis of United States (US) airway registries are often difficult to interpret but, of the two largest published recently, one study from 2011 reports 10,356 intubation attempts [19] and one from 2014 reports 74,993 intubation attempts [20]. The 2011 data from Wang et al. suggest that the major indication for intubation is cardiac arrest and this is supported by the 2014 data from Diggs et al., with the studies reporting that 53 and $52 \%$ of patients respectively are intubated following a cardiac arrest. The frequency of intubation following trauma is also similar between the two studies - 6 and $8 \%[19,20]$. Outside the US, one of the largest pre-hospital emergency airway studies of the last 5 years comes from Sunde et al. reporting data on 2327 intubations from multiple centres. In this study, $55 \%$ of patients were intubated for medical reasons, of whom $62 \%$ were in cardiac arrest. The remaining $45 \%$ of patients are intubated following traumatic injury, of who $56 \%$ are in cardiac arrest [21].

There are circumstances in which early intubation may not be in the patient's best interests. There is data to suggest that patients with significant hypovolaemia following traumatic injury may have a higher mortality if anaesthetised in the pre-hospital setting, and that shorter scene times and waiting until arrival at hospital with direct access to definitive surgical intervention may be preferable for this patient group [22, 23].

\section{How should it be done?}

The question of the optimal techniques for pre-hospital airway management remain much debated. The majority of studies in this area focus on out-of-hospital cardiac arrest and only a small number describe techniques used for trauma patients. Some studies which compare the use of bag-valve mask (BVM) ventilation with advanced airway management techniques found no benefit of advanced airway techniques over BVM ventilation $[3,24]$ but other studies do suggest a morbidity and mortality benefit associated with the use of advanced airway techniques for all severely-injured patients [25-27] and for those patients with traumatic brain injury if performed by personnel with appropriate training and experience $[4,28,29]$. Those studies that focus on out-of-hospital cardiac arrest also do not conclusively show a benefit of advanced techniques over basic techniques but the inability to adjust for confounders is widely acknowledged [30-32]. A UK-based study assessing the use of supraglottic airway devices for non-traumatic out-of-hospital cardiac arrest failed to demonstrate superiority when compared with tracheal intubation [33]. In contrast, data from the United States suggested improved 72-h survival using supraglottic airway devices when compared to tracheal intubation [34]. Data published in 2018 from a trial comparing bag-valve-mask ventilation with tracheal intubation for initial airway management was inconclusive [35].

PHEA is usually performed using an induction agent, often ketamine, a neuromuscular blocker and a sedative agent. As with in-hospital practice, the majority of agents can be safely used in a pre-hospital setting as long as careful attention is given to the dose of drug administered, to reflect the deranged physiology of severely-injured patients. The use of ketamine as an induction agent has historically been associated with an increase in intracranial pressure [36]. More recent studies suggest these concerns are not associated with any clinical significance and ketamine is now considered a safe and effective drug for use in the pre-hospital setting 
[37], particularly in haemodynamically unstable patients [38]. Rocuronium is the neuromuscular blocking agent of choice for many and a combination of fentanyl, ketamine, and rocuronium has been shown to produce more favourable intubating conditions in the pre-hospital setting [39].

All efforts should be focused on making the first attempt at laryngoscopy successful, as repeated attempts have been shown to be detrimental both in terms of morbidity and mortality [40, 41]. Multiple attempts at laryngoscopy can cause bleeding or swelling in the airway and may result in significant desaturation and hypoxic episodes [42]. Laryngoscopy is highly stimulating for patients and causes a sympathetic surge. Perkins et al. demonstrated a hypertensive response to pre-hospital laryngoscopy and intubation in $79 \%$ of severely injured patients, and $9 \%$ of patients experienced a greater than $100 \%$ increase in mean arterial pressure and/or systolic blood pressure [43]. Impairment of cerebral autoregulation following traumatic brain injury leaves the brain vulnerable to surges in blood pressure and intracranial pressure, with a subsequent worsening of cerebral oedema and haematoma expansion, which can be detrimental to patient outcome [43-45]. The hypertensive response to laryngoscopy is arguably more common in emergency settings, where the dose of induction agent may be modified if there are significant concerns about the severity of injury and the likely physiological response to anaesthesia. Opioids which suppress the hypertensive response, may be given in low doses or omitted altogether.

A robust failed intubation plan should be well-embedded into all services delivering PHEA. This plan should be verbalised to the attending team before starting PHEA. Videolaryngoscopy may be considered as part of a failed intubation plan or may at times be used for the first attempt at laryngoscopy. The benefit of videolaryngoscopy for emergency airway management remains widely debated but recent evidence does not strongly support a positive benefit of this intervention [46-48]. Emergency cricothyroidotomy is generally the endpoint of failed intubation guidelines $[49,50]$. The evidence-base for this technique remains small and no clear benefit of a surgical technique has been demonstrated over needle technique however the increased number of complications associated with needle cricothyroidotomy and the requirement for conversion to a surgical technique means that a surgical technique is recommended by major airway guidelines $[49,51]$.

\section{Who should deliver it?}

There is ongoing debate about who should deliver prehospital advanced airway management and the amount of training required and consensus has not been reached.
Recommendations in recent UK guidelines suggest that the standard of care delivered in the pre-hospital setting should be the same as that delivered in-hospital and doctors providing emergency anaesthesia should be able to do so competently, and unsupervised, in the emergency department [50, 52]. Recognition of Pre-hospital Emergency Medicine (PHEM) as a subspecialty in the UK has helped structure and formalise training programmes in pre-hospital care to improve the care delivered to patients. In Europe, pre-hospital emergency care is increasingly delivered by physicians [53]. There is evidence to suggest higher success rates and shorter on scene times for PHEA when this technique is delivered by physicians [54]. A median intubation success rate of $98.8 \%$ (range $78.1-100 \%$ ) has been reported for physicians performing intubations in the pre-hospital setting. The reported median success rate for non-physicians is $91.7 \%$ (range 61.6 to $100 \%$ ) [9]. As expected, success rates are generally higher for anaesthetists when compared with non-anaesthetists [53, 55], emphasising the importance of increased clinical exposure in the preservation of skills, and avoidance of skill fade [56]. In recognition of the fact that intubation without the use of drugs is generally futile [6], the Joint Royal Colleges Ambulance Liaison Committee no longer train paramedics in tracheal intubation but recommend the use of supraglottic airway devices for advanced airway management [57].

\section{How can practice be improved? Standards and safety}

PHEA has become increasingly formalised and guidelines exist at local and national levels to standardise the procedure and improve patient safety [50, 52, 58]. The pre-hospital infrastructure in the United States differs significantly from that in Europe and Australasia and although the guidelines reflect those differences, the general messages delivered are similar in all the guidelines. There is a strong focus on patient safety, the guidelines suggest that advanced airway management should only be delivered when appropriately skilled pre-hospital personnel are available. Otherwise meticulous attention should be paid to performing high-quality basic airway interventions [50, 52, 58, 59]. Studies which have reviewed the implementation and effectiveness of these tools within pre-hospital services have been able to demonstrate uncomplicated introduction process [60] and improvement in compliance with guideline standards $[61,62]$.

\section{Apnoeic oxygenation}

Severely injured patients with significant physiological and anatomical derangement, are more susceptible to adverse events during emergency anaesthesia. Anatomical distortion of the head and neck from injury may 
impede intubation, and chest injury may cause ventilationperfusion mismatch. Hypoxia is one of the most commonly occurring adverse event during emergency intubation and is reported to occur in over one quarter of emergency intubations [63, 64]. Whilst any given reduction in the partial pressure of arterial oxygen will reduce arterial oxygen saturation, the magnitude of this fall increases once $\mathrm{SaO}_{2}$ falls below 93\% [65]. Increasing the time to desaturation during prolonged or difficult intubation using apnoeic oxygenation has been demonstrated to increase peri-intubation oxygen saturation and reduce the incidence of hypoxaemia. The technique, though simple to perform, remains relatively underused in the pre-hospital setting. One retrospective study reported a $6 \%$ reduction in episodes of desaturation associated with emergency intubations [66]. Further studies are being conducted to evaluate its use in the pre-hospital environment.

\section{Post intubation care}

In line with in-hospital practice, there is an increasing focus on post-intubation care. If possible, post intubation care should begin in the pre-hospital phase. Patients should be appropriately sedated using an anaesthetic agent following intubation, the dose of which is titrated to their haemodynamic physiology. Further doses of neuromuscular blocking agents may also be required to enable mandatory ventilation and avoid any ventilatory compromise. The use of end-tidal carbon dioxide monitoring, has become mandatory in any intubated patient and careful attention should be paid to the provision of appropriate ventilation strategies, incorporating lung protective ventilation if possible. Emerging evidence about the harmful effects of hyperoxia may guide future practice, particularly in patients with traumatic brain injury where a $\mathrm{PaO}_{2}$ greater than $65 \mathrm{kPa}$ (or $487 \mathrm{mmHg}$ ) has been shown to worsen patient outcome [67]. Ventilation should be carefully managed to avoid hypocarbia and hypercarbia, both of which have been demonstrated to be detrimental, particularly in traumatic brain injury [68-70]. Mechanical ventilation is generally considered to be superior to hand ventilation when targeting a specific range for end-tidal carbon dioxide [71]. One Scandinavian service demonstrated increased use of mechanical ventilation following the introduction of an standard operating procedure [62].

Body temperature should be maintained in the pre-hospital setting. Recent data has demonstrated a higher rate of hypothermia in patients who are anaesthetised outside hospital [62]. Previously cooling patients with traumatic brain injury or post cardiac arrest was considered to be beneficial to outcome but subsequent studies have questioned this theory and it is no longer recommended practice $[72,73]$.

\section{Reporting data}

The standardised reporting of data for pre-hospital advanced airway management remains poor despite recent major guidelines promoting the use of key performance indicators [52]. In 2009, Sollid et al. developed an Utstein-style template for documenting and reporting pre-hospital airway management [11], but to date its use remains limited with relatively few studies reporting data in accordance with the template. The template has been recently revised [74] and improvements in data collection and reporting will make the evidence-base for pre-hospital advanced airway management more robust and provide better indications of the benefits and pitfalls of this intervention.

\section{Conclusion}

PHEA remains a controversial area with a limited evidence-base but current data suggests an unmet demand for PHEA in a small but identifiable group of patients. Where necessary, the intervention should be delivered by personnel with the appropriate skills and training. Careful attention should be given to optimising the first attempt at laryngoscopy and the intervention should be delivered to the same standards as those achieved in hospital. The increasing numbers of physicians in Pre-hospital Emergency Medicine should help improve the delivery of PHEA, which will hopefully translate into improvement in morbidity and mortality.

\section{Abbreviations}

BVM: Bag-valve-mask; GCS: Glasgow Coma Scale; $\mathrm{PaO}_{2}$ : Arterial partial pressure of oxygen; PHEA: Pre-hospital Emergency Anaesthesia; PHEM: Pre-hospital Emergency Medicine

\section{Availability of data and materials}

Data sharing is not applicable to this article as no datasets were generated or analysed during the current study.

\section{Authors' contributions}

$K C$ reviewed the evidence and authored the first draft. MR and DL reviewed and constructively criticised the first draft and co-authored subsequent drafts. All authors read and approved the final manuscript.

Ethics approval and consent to participate Not applicable

\section{Consent for publication}

Not applicable

\section{Competing interests}

The authors declare that they have no competing interests.

\section{Publisher's Note}

Springer Nature remains neutral with regard to jurisdictional claims in published maps and institutional affiliations.

\section{Author details}

'Department of Anaesthesia, North Bristol NHS Trust, Southmead Hospital, Southmead Way, Bristol BS10 5NB, UK. '2Department of Research, Norwegian Air Ambulance Foundation, Drøbak, Norway. ${ }^{3}$ Pre-hospital Division, Air Ambulance Department, Oslo University Hospital, Oslo, Norway. ${ }^{4}$ Faculty of 
Health Sciences, University of Stavanger, Stavanger, Norway. ${ }^{5}$ Bristol University, Bristol, UK.

\section{Received: 23 July 2018 Accepted: 4 October 2018 Published online: 20 October 2018}

\section{References}

1. Hussmann B, Lefering R, Waydhas C, Ruchholtz S, Wafaisade A, Kauther MD, et al. Prehospital intubation of the moderately injured patient: a cause of morbidity? A matched-pairs analysis of 1,200 patients from the DGU trauma registry. Crit Care. 2011;15:R207.

2. Pepe PE. Prehospital endotracheal intubation: elemental or detrimental? Crit Care. 2015;19:121.

3. Stockinger ZT, MCSwain NE Jr. Prehospital endotracheal intubation for trauma does not improve survival over bag-valve-mask ventilation. J Trauma. 2004;56: 531-6.

4. Bossers SM, Schwarte LA, Loer SA, Twisk JWR, Boer C, Schober P. Experience in prehospital endotracheal intubation significantly influences mortality of patients with severe traumatic brain injury: a systematic review and metaanalysis. PLoS One. 2015;10:e0141034-26.

5. Lockey DJ, Healey B, Crewdson K, Chalk G, Weaver AE, Davies GE. Advanced airway management is necessary in prehospital trauma patients. $\mathrm{Br} J$ Anaesth. 2015;114:657-62

6. Lockey D, Davies G, Coats T. Survival of trauma patients who have prehospital tracheal intubation without anaesthesia or muscle relaxants: observational study. BMJ. 2001:323:141.

7. Christensen EF, Høyer CCS. Prehospital tracheal intubation in severely injured patients: a Danish observational study. BMJ. 2003;327:533.

8. Hubble MW, Brown L, Wilfong DA, Hertelendy A, Benner RW, Richards ME. A meta-analysis of prehospital airway control techniques part I: Orotracheal and Nasotracheal intubation success rates. Prehosp Emerg Care. 2010;14:377-401.

9. Crewdson K, Lockey DJ, Røislien J, Lossius HM, Rehn M. The success of prehospital tracheal intubation by different pre-hospital providers: a systematic literature review and meta-analysis. Crit Care. 2017;21:1-10.

10. Fevang E, Lockey D, Thompson J, Lossius HM, Collaboration TTR. The top five research priorities in physician-provided pre-hospital critical care: a consensus report from a European research collaboration. Scand J Trauma Resusc Emerg Med. 2011;19:57.

11. Sollid SJM, Lockey D, Lossius HM. Pre-hospital advanced airway management expert group. A consensus-based template for uniform reporting of data from pre-hospital advanced airway management. Scand J Trauma Resusc Emerg Med. 2009;17:58

12. Lockey DJ. Research questions in pre-hospital trauma care. PLoS Med. 2017; 14:e1002345-4.

13. Swain SA, Stiff G. Issues and challenges for research in major trauma. Emerg Med J. 2018;35:267-9.

14. Stephens CT, Kahntroff S, Dutton RP. The success of emergency endotracheal intubation in trauma patients: a 10-year experience at a major adult trauma referral center. Anesth Analg. 2009;109:866-72.

15. Sise MJ, Shackford SR, Sise CB, Sack DI, Paci GM, Yale RS, et al. Early intubation in the Management of Trauma Patients: indications and outcomes in 1,000 consecutive patients. J Trauma. 2009:66:32-40.

16. Cook TM, Woodall N, Harper J, Benger J. Major complications of airway management in the UK: results of the fourth National Audit Project of the Royal College of Anaesthetists and the difficult airway society. Part 2: intensive care and emergency departments. Br J Anaesth. 2011;106:632-42.

17. Struck MF, Fakler JKM, Bernhard M, Busch T, Stumpp P, Hempel G, et al. Mechanical complications and outcomes following invasive emergency procedures in severely injured trauma patients. Nat Sci Rep. 2018:1-10.

18. Mayglothling J, Duane TM, Gibbs M, McCunn M, Legome E, Eastman AL, et al. Emergency tracheal intubation immediately following traumatic injury: Eastern Association for the Surgery of Trauma practice management guideline. J Trauma Acute Care Surg. 2012:S333-40.

19. Wang HE, Mann NC, Mears G, Jacobson K, Yealy DM. Out-of-hospital airway management in the United States. Resuscitation. 2011;82:378-85.

20. Diggs LA, Yusuf J-EW, De Leo G. An update on out-of-hospital airway management practices in the United States. Resuscitation. 2014;85:885-92.

21. Sunde GA, Heltne JK, Lockey D, Burns B, Sandberg M, Fredriksen K, et al. Airway management by physician-staffed helicopter emergency medical services - a prospective, multicentre, observational study of 2,327 patients. Scand J Trauma Resusc Emerg Med. 2015;23:57.
22. Crewdson K, Rehn M, BROHI K, Lockey DJ. Pre-hospital emergency anaesthesia in awake hypotensive trauma patients: beneficial or detrimental? Acta Anaesthesiol Scand. 2018;62:504-14.

23. Chou D, Harada MY, Barmparas G, Ko A, Ley EJ, Margulies DR, et al. Field intubation in civilian patients with hemorrhagic shock is associated with higher mortality. Journal Trauma Acute Care Surg. 2016;80:278-82.

24. Bochicchio GV, Ilahi O, Joshi M, Bochicchio K, Scalea TM. Endotracheal intubation in the field does not improve outcome in trauma patients who present without an acutely lethal traumatic brain injury. J Trauma. 2003;54:307-11.

25. Winchell RJ, Hoyt DB. Endotracheal intubation in the field improves survival in patients with severe head injury. Trauma research and Education Foundation of san Diego. Arch Surg. 1997;132:592-7.

26. Meizoso JP, Valle EJ, Allen CJ, Ray JJ, Jouria JM, Teisch LF, et al. Decreased mortality after prehospital interventions in severely injured trauma patients. J Trauma Acute Care Surg. 2015;79:227-31.

27. Hartog Den D, Romeo J, Ringburg AN, Verhofstad MHJ, Van Lieshout EMM. Survival benefit of physician-staffed helicopter emergency medical services (HEMS) assistance for severely injured patients. Injury. 2015;46:1281-6.

28. Bernard SA, Nguyen V, Cameron P, Masci K, Fitzgerald M, Cooper DJ, et al. Prehospital rapid sequence intubation improves functional outcome for patients with severe traumatic brain injury: a randomized controlled trial. Ann Surg. 2010;252:959-65.

29. Davis DP, Peay J, Sise MJ, Kennedy F, Simon F, Tominaga G, et al. Prehospital airway and ventilation management: a trauma score and injury severity scorebased analysis. J Trauma. 2010;69:294-301.

30. Fouche PF, Simpson PM, Bendall J, Thomas RE, Cone DC, SAR D. Airways in out-of-hospital cardiac arrest: systematic review and meta-analysis. Prehosp Emerg Care. 2014;18:244-56.

31. Carlson JN, Reynolds JC. Does advanced airway management improve outcomes in adult out-of-hospital cardiac arrest? Ann Emerg Med. 2014; 64(2):163-4.

32. Hasegawa K, Hiraide A, Chang Y, Brown DFM. Association of prehospital advanced airway management with neurologic outcome and survival in patients with out-of-hospital cardiac arrest. JAMA 2013;309:257-66.

33. Benger JR, Kirby K, Black S, Brett SJ, Clout M, Lazaroo MJ, Nolan JP, Reeves BC, Robinson M, Scott $\sqcup$, Smartt H. Effect of a strategy of a Supraglottic airway device vs tracheal intubation during out-of-hospital cardiac arrest on functional outcome: the AIRWAYS-2 randomized clinical trial. JAMA. 320(8):779-91.

34. Wang HE, Schmicker RH, Daya MR, Stephens SW, Idris AH, Carlson JN, Colella MR, Herren H, Hansen M, Richmond NJ, Puyana JC. Effect of a strategy of initial laryngeal tube insertion vs endotracheal intubation on 72-hour survival in adults with out-of-hospital cardiac arrest: a randomized clinical trial. JAMA. 2018;320(8):769-78.

35. Jabre P, Penaloza A, Pinero D, Duchateau FX, Borron SW, Javaudin F, Richard O, de Longueville D, Bouilleau G, Devaud ML, Heidet M. Effect of bag-mask ventilation vs endotracheal intubation during cardiopulmonary resuscitation on neurological outcome after out-of-hospital cardiorespiratory arrest: a randomized clinical trial. JAMA;319(8):779-87.

36. Schwedler M, Miletich DJ, Albrecht RF. Cerebral blood flow and metabolism following ketamine administration. Can Anaesth Soc J. 1982;29:222-6.

37. Zeiler FA, Teitelbaum J, West M, Gillman LM. The ketamine effect on ICP in traumatic brain injury. Neurocrit Care. 2014;21:163-73.

38. Paal P, Herff H, Mitterlechner T, Goedecke Von A, Brugger H, Lindner KH, et al. Anaesthesia in prehospital emergencies and in the emergency room. Resuscitation. 2010;81:148-54.

39. Lyon RM, Perkins ZB, Chatterjee D, Lockey DJ, Russell MQ, Kent S, Sussex Air Ambulance Trust. Significant modification of traditional rapid sequence induction improves safety and effectiveness of pre-hospital trauma anaesthesia. Crit Care. 2015;19:134

40. Mort TC. Emergency tracheal intubation: complications associated with repeated laryngoscopic attempts. Anaes Analg. 2004;99:607-13.

41. Hasegawa K, Shigemitsu K, Hagiwara Y, Chiba T, Watase H, Brown CA, et al. Association between repeated intubation attempts and adverse events in emergency departments: an analysis of a multicenter prospective observational study. Ann Emerg Med. 2012;60:749-754.e2.

42. Bernhard M, Becker TK, Gries A, Knapp J, Wenzel V. The first shot is often the best shot: first-pass intubation success in emergency airway management. Anesth Analg. 2015;121:1389-93.

43. Perkins ZB, Gunning M, Crilly J, Lockey D, O'Brien B. The haemodynamic response to pre-hospital RSI in injured patients. Injury. 2012;44:618-23. 
44. Chesnut RM, Marshall LF, Klauber MR, Blunt BA, Baldwin N, Eisenberg HM, et al. The role of secondary brain injury in determining outcome from severe head injury. J Trauma. 1993;34:216-22.

45. Perel P, Roberts I, Bouamra O, Woodford M, Mooney J, Lecky F. Intracranial bleeding in patients with traumatic brain injury: a prognostic study. BMC Emerg Med. 2009;9:1321-8.

46. Savino PB, Reichelderfer S, Mercer MP, Wang RC, Sporer KA. Direct versus video laryngoscopy for prehospital intubation: a systematic review and meta-analysis. Acad Emerg Med. 2017;24:1018-26.

47. Jiang J, Ma D, Li B, Yue Y, Xue F. Video laryngoscopy does not improve the intubation outcomes in emergency and critical patients - a systematic review and meta-analysis of randomized controlled trials. Crit Care. 2017;21:288.

48. Lascarrou JB, Boisrame-Helms J, Bailly A, Le Thuaut A, Kamel T, Mercier E, et al. Video laryngoscopy vs direct laryngoscopy on successful first-pass Orotracheal intubation among ICU patients. JAMA. 2017:317:483-11.

49. Higgs A, McGrath BA, Goddard C, Rangasami J, Suntharalingam G, Gale R, et al. Guidelines for the management of tracheal intubation in critically ill adults. Br J Anaesth. 2018;120:323-52.

50. Rehn M, Hyldmo PK, Magnusson V, Kurola J, Kongstad P, Rognås L, et al. Scandinavian SSAI clinical practice guideline on pre-hospital airway management. Acta Anaesthesiol Scand. 2016;60:852-64.

51. Truhlář A, Deakin CD, Soar J, Khalifa GEA, Alfonzo A, Bierens JJLM, et al. European resuscitation council guidelines for resuscitation 2015: section 4. Cardiac arrest in special circumstances. Resuscitation. 2015;95:148-201.

52. Lockey DJ, Crewdson K, Davies G, Jenkins B, Klein J, Laird C, et al. AAGBI: safer pre-hospital anaesthesia 2017. Anaesthesia. 2017;72:379-90.

53. Sollid SJM, Rehn M. The role of the anaesthesiologist in air ambulance medicine. Curr Opin Anaesthesiol. 2017;30:513-7.

54. Gellerfors M, Fevang E, Bäckman A, Krüger A, Mikkelsen S, Nurmi J, et al. Pre-hospital advanced airway management by anaesthetist and nurse anaesthetist critical care teams: a prospective observational study of 2028 pre-hospital tracheal intubations. Br J Anaesth. 2018;120:1103-9.

55. Lockey D, Crewdson K, Weaver A, Davies G. Observational study of the success rates of intubation and failed intubation airway rescue techniques in 7256 attempted intubations of trauma patients by pre-hospital physicians. Br J Anaesth. 2014;113:220-5.

56. Breckwoldt J, Klemstein S, Brunne B, Schnitzer L, Arntz H-R, Mochmann H-C. Expertise in prehospital endotracheal intubation by emergency medicine physicians_comparing 'proficient performers' and 'experts'. Resuscitation. 2012:83:434-9.

57. Deakin CD, Clarke T, Nolan J, Zideman DA, Gwinnutt C, Moore F, et al. A critical reassessment of ambulance service airway management in prehospital care: joint Royal Colleges Ambulance Liaison Committee Airway Working Group, June 2008. Emerg Med J. 2010;27:226-33.

58. Hossfeld B, Bein B, Boettiger BW, Bohn A, Fischer M, Graesner J-T, et al. Recommended practice for out-of-hospital emergency anaesthesia in adults: statement from the out-of-hospital emergency Anaesthesia working Group of the Emergency Medicine Research Group of the German Society of Anaesthesiology and Intensive Care. Eur J Anaesthesiol. 2016;33:881-97.

59. O'Connor RE. Drug-assisted intubation in the prehospital setting position statement of the National Association of emergency physicians. Prehosp Emerg Care. 2006;10:260-0.

60. Chesters A, Keefe N, Mauger J, Lockey D. Prehospital anaesthesia performed in a rural and suburban air ambulance service staffed by a physician and paramedic: a 16-month review of practice. Emerg Med J. 2014;31:65-8.

61. Chen C, Kan T, Li S, Qiu C, Gui L. Use and implementation of standard operating procedures and checklists in prehospital emergency medicine: a literature review. Am J Emerg Med. 2016;34:2432-9.

62. Rognås L, Hansen TM, Kirkegaard H, Tønnesen E. Standard operating procedure changed pre-hospital critical care anaesthesiologists' behaviour: a quality contro study. Scand J Trauma Resusc Emerg Med. 2013;21(1):84.

63. Jaber S, Amraoui J, Lefrant J-Y, Arich C, Cohendy R, Landreau L, et al. Clinical practice and risk factors for immediate complications of endotracheal intubation in the intensive care unit: a prospective, multiple-center study. Crit Care Med. 2006;34:2355-61.

64. Griesdale DEG, Bosma TL, Kurth T, Isac G, Chittock DR. Complications of endotracheal intubation in the critically ill. Intensive Care Med. 2008;34: 1835-42.

65. Davis DP, Hwang JQ, Dunford JV. Rate of decline in oxygen saturation at various pulse oximetry values with prehospital rapid sequence intubation. Prehosp Emerg Care. 2008;12:46-51.
66. Wimalasena Y, Burns B, Reid C, Ware S, Habig K. Apneic oxygenation was associated with decreased desaturation rates during rapid sequence intubation by an Australian helicopter emergency medicine service. Ann Emerg Med. 2015;65:371-6.

67. Vincent J-L, Taccone FS, He X. Harmful effects of Hyperoxia in Postcardiac arrest, Sepsis, traumatic brain injury, or stroke: the importance of individualized oxygen therapy in critically ill patients. Can Respir J. 2017;2017:1-7.

68. Davis DP, Idris AH, Sise MJ, Kennedy F, Eastman AB, Velky T, et al. Early ventilation and outcome in patients with moderate to severe traumatic brain injury. Crit Care Med. 2006;34:1202-8.

69. Warner KJ, Cuschieri J, Copass MK, Jurkovich GJ, Bulger EM. The impact of prehospital ventilation on outcome after severe traumatic brain injury. J Trauma. 2007;62:1330-8.

70. Deakin CD, Sado DM, Coats TJ, Davies G. Prehospital end-tidal carbon dioxide concentration and outcome in major trauma. J Trauma. 2004;57:65-8.

71. DP, De Cosmo D, Bossi A. Comparison of manual and mechanical ventilation during transport of patients to the intensive care unit after cardiac surgery. Eur J Anaesthesiol. 2006;38:1-47.

72. Langhelle A, Lockey D, Harris T, Davies G. Body temperature of trauma patients on admission to hospital: a comparison of anaesthetised and nonanaesthetised patients. Emerg Med J. 2012;29:239-42.

73. Lindsay PJ, Buell D, Scales DC. The efficacy and safety of pre-hospital cooling after out-of-hospital cardiac arrest: a systematic review and metaanalysis. Crit Care. 2018;22:66.

74. Carney N, Totten AM, O'Reilly C, Ullman JS, Hawryluk GWJ, Bell MJ, et al. Guidelines for the Management of Severe Traumatic Brain Injury. Neurosurgery. 2017;80:6-15.

\section{Ready to submit your research? Choose BMC and benefit from:}

- fast, convenient online submission

- thorough peer review by experienced researchers in your field

- rapid publication on acceptance

- support for research data, including large and complex data types

- gold Open Access which fosters wider collaboration and increased citations

- maximum visibility for your research: over $100 \mathrm{M}$ website views per year

At BMC, research is always in progress.

Learn more biomedcentral.com/submissions 